\title{
СОВРЕМЕННЫЕ ФОРМЫ ПРОВЕДЕНИЯ КОРПОРАТИВНЫХ МЕРОПРИЯТИЙ В БИЗНЕС-ОРГАНИЗАЦИИ
}

\section{MODERN FORMS OF HOLDING CORPORATE EVENTS IN A BUSINESS ORGANIZATION}

\section{O. Kiryanova}

Summary: The author of the article discusses the modern forms of holding corporate events in a business organization. The main focus is on the description of the goals, tasks, and functions of corporate events, the concept of «event» is disclosed and the features of the activity of an event agency for organizing corporate events for a business organization are considered. The author concludes that a well-thought-out system of organizing and conducting corporate events plays an important role in the process of cultivating corporate values, in forming loyalty and trust of employees to the management of a business organization, increasing motivation and satisfaction from working in a business organization, and uniting employees for effective and efficient activities of a business organization.

Keywords: corporate culture, corporate event, corporate event goals, event agency.
Кирьянова Ольга Александровна

К.n.н., преподаватель, Байкальский Государственный Университет, г. Иркутск s-slon@bk.ru

Аннотация: Автор статьи рассуждает о современных формах проведения корпоративных мероприятий в бизнес-организации. Основной акцент сделан на описание целей, задач и функций корпоративных мероприятий, раскрыто понятия «ивент» и рассмотрены особенности деятельности ивентагентства по организации корпоративных мероприятий для бизнес-организации. Автор делает вывод о том, что продуманная система организации и проведения корпоративных мероприятий играет важную роль в процессе культивирования корпоративных ценностей, в формировании лояльности и доверия сотрудников руководству бизнес-организации, повышении мотивации и уровня удовлетворения от работы в бизнес-организации, объединения сотрудников для эффективной и результативной деятельности бизнес-организации.

Ключевые слова: корпоративная культура, корпоративное мероприятие, цели корпоративного мероприятия, ивент-агентство.

профессиональную миссию.

Корпоративная культура бизнес-организации выступает как совокупность значений, образов, символов эталонного корпоративного сознания в той или иной степени полноты, присваиваемых конкретным сотрудником и персоналом бизнес-организации в целом. Преломляясь через систему индивидуальных ценностей, через мировоззрение сотрудника, пространство организационной (корпоративной) культуры формирует системы ценностных представлений и индивидуальные ценностные пространства, обретающее личностный смысл и задающее специфическое ценностное отношение сотрудников к организационной жизнедеятельности. Именно изменение ценностного отношения сотрудников, то есть выработка новой системы ценностей, в рамках корпоративного сознания и представляет собой задачу развития организационно (корпоративной) культуры в бизнес-организациях через продуманное проведение различных по форме и содержанию корпоративных мероприятий как практического инструмента для формирования и усиления корпоративной культуры бизнес-организации.

Корпоративные мероприятия - это один из главных инструментов создания, формирования, развития корпоративной культуры, трансляции ценностей бизнес-ор- 
ганизации как своим сотрудникам, так и потребителям товаров или услуг, поставщикам, конкурентам, подрядчикам. Корпоративным мероприятием можно считать любое событие в жизни бизнес-организации, которое не связано с выполнением профессиональных задач и в котором участвуют ее сотрудники. Корпоративные мероприятия позволяют успешно решать такие задачи, как повышение лояльности к компании, нематериальная мотивация сотрудников, командообразование.

Мероприятие - это специально организованное действие для осуществления какой-либо цели.

Корпоративное мероприятие - это специально организованное действие или совокупность действий для осуществления конкретной, важной и актуальной цели для бизнес-организации.

Основные цели организации и проведения корпоративных мероприятий:

1. Сплотить коллектив бизнес-организации. Корпоративное мероприятие работает как эффективный инструмент только в том случае, если на этапе подготовки организаторы четко сформулируют цели и задачи, которые могут быть решены с помощью корпоративного мероприятия.

2. Отметить лучших сотрудников. Корпоративное мероприятие помогает руководству бизнес-организации проявить свое расположение и заботу о сотрудниках, помогает наглядно продемонстрировать благодарность руководства как к команде сотрудников, персонала вместе, так и индивидуально, поощрить, наградить, отметить, поблагодарить за работу в бизнес-организации.

3. Наладить коммуникации. Между молодым и старшим поколениями, между разрозненными отделами, между новичками и опытными работниками, вовлечь в мероприятие коллектив и дать возможность неформального общения.

4. Познакомить сотрудников с изменениями, нововведениями, реорганизацией, новыми назначениями. Запланированные как часть мероприятия такие новости воспринимаются спокойнее, позволяют наладить неформальные коммуникации.

Корпоративное мероприятие - это социально-культурный феномен, который объединяет в себе несколько функций:

1. Функция объединения. На корпоративном мероприятии сотрудники бизнес-организации находятся вместе не формально, в рамках статуса, уровня должности, опыта, стажа, роли в бизнесорганизации, а на равных, как сотрудники коллектива бизнес-организации. Одновременно и вместе получают развлекательную, познавательную или обучающую информацию, все вместе ее пере- живают или погружаются в предлагаемые обстоятельства корпоративного мероприятия, взаимодействуют и тем самым сближаются друг с другом.

2. Функция просвещения. На каждом мероприятии сотрудники получают какую-то новую информацию о самой бизнес-организации, ее успехах, результатах, количественных и качественных показателях работы; о целях и задачах своей деятельности в коллективе бизнес-организации, о истории ее создания, а также о миссии, целях и бизнес-процессах, в которые они включены. Новая информация присутствует и в развлекательных, календарных праздниках, сотрудники бизнес-организации прирастают новыми знаниями, которые воспринимаются лучше и полнее в неформальной обстановке.

3. Функция развлечения. На каждом корпоративном мероприятии, даже делового и развлекательного формата есть развлекательные части, которые позволяют сотрудникам бизнес-организации переключиться из реальности в плоскость воображения, забыть на время о действительности и получить удовольствие от предлагаемых развлечений.

4. Функция релакса, расслабления. Корпоративные мероприятия переключают восприятие и внимание сотрудников на неформальные отношения и взаимодействие, предлагают другие, отличные от профессиональных действия и возможности, раскрывают индивидуальные возможности сотрудников. Корпоративное мероприятие дает возможность персоналу бизнес-организации побыть в безопасной среде со «своими» людьми, на одной волне и отключиться от забот, проблем, суеты, и почувствовать нужность и важность своей работы, личности, участия в работе бизнес-организации.

5. Функция раскрытия потенциала. Некоторые корпоративные мероприятия предполагают различные организационные задания или творческие конкурсы, которые позволяют сотрудникам проявить свои творческие способности, лидерские и организационные качества.

6. Функция мотивации на дальнейшую деятельность в бизнес-организации. В результате грамотно проведенного мероприятия, на котором сотрудник получил признание, развлечение, обучение или неформальное общение, у сотрудников возникает благодарность к бизнес-организации, вдохновение и мотивация продолжать трудиться в ней и дальше и становиться «адвокатом бренда» - популяризатором идей, продуктов, товаром или услуг бизнес-организации.

Корпоративные мероприятия помогают бизнес-организации создать положительный имидж как внешний, 
работающий на репутацию, так и внутренний, работающий на сотрудников, персонал организации, повышая мотивацию работать и удерживая сотрудников на своих местах и должностях.

Организацией корпоративных мероприятий для бизнес-организаций занимается отдельный сектор экономики, специализирующийся на услугах по подготовке и проведению мероприятий различных форматов, видов, жанров и уровней, это - ивент-агенства.

Event (с англ. «событие») - публичное мероприятие, которое носит развлекательный, деловой и/или рекламный характер.

В России ивент-индустрия начала развиваться в конце 20 века, когда на рынке появился спрос на организаторов, ивент-менеджеров и компании, ивент-агентства, предоставляющие услуги по организации мероприятий. Большинство ивент-агентств специализируются на рынке «B2В», что переводиться как «бизнес для бизнеса», где одна бизнес-организация, заказчик корпоративного мероприятия, приобретает у другой бизнес-организации, исполнителя, подрядчика, поставщика, набор услуг по организации, подготовке, контролю и проведению части корпоративного мероприятия или всего мероприятия в целом. На оказание услуг по организации и проведению мероприятия заключается Договор возмездного оказания услуг, расчет за оказанные услуги производиться по безналичной форме оплаты на основании подписанного сторонами Акта приемки и сдачи оказанных услуг. Ивентагентства могут быть по своему профилю деятельности узкоспециализированными, например, организовывать и проводить только выездные командообразующие или только деловые мероприятия, или многопрофильными, выполняющими заказы на проведение различных по видам и жанрам корпоративных мероприятий: тематические праздники, профессиональные конкурсы, презентации и другие.

При организации и проведении корпоративного мероприятия любого вида или жанра, ивент-агентство учитывает правило «4-Р», уточняет у заказчика 4 главных компонента: место (Place), цели и принципы (Principles), программа (Programm) и участники (Participants). Уточнение содержания и наполнения каждого из элементов «4-Р» системы гарантирует успех корпоративному мероприятию и достижение поставленных целей его проведения.

Значимость и событийность корпоративного мероприятия определяются общими принципами, которые помогают на этапе подготовки проверить его содержание, наполнение, цели, задачи, способы организации и вовлечение сотрудников:
- абсолютная добровольность участия и согласие на все принимаемые обязательные и условные правила поведения на мероприятии;

- свободный выбор разнообразных сюжетов, ролей, положений, предложений, отличных от видов и результатов бизнес-процессов, от деятельности бизнес-организации;

- возможность для каждого участника корпоративного мероприятия иметь пространство, время и место для творческого выхода своей индивидуальности или личного участия в какой-либо из частей мероприятия;

- системность, цикличность и целесообразность в проведении корпоративных мероприятия с учетом календарных праздников, профессиональных праздников, календаря обучающих и деловых мероприятий;

- коммуникативный характер проводимых корпоративных мероприятий и событий, предполагающий максимальные возможности для неформального общения, свободы самовыражения, творчества, лидерских и организационных качеств.

- учет в корпоративных мероприятия традиций, вбирающих в себя ритуалы, церемонии, символов и атрибутов корпоративного стиля бизнес-организации.

Постановка целей - главный ориентир и отправная точка в процессе подготовки и реализации корпоративного мероприятия. Перед созданием концепции мероприятия заказчик, руководитель бизнес-организации и ивент-организатор, представитель ивент-агентства уточняют и согласовывают цель проведения корпоративного мероприятия. Ивент-организатор доводит главную цель до всех участниками процесса организации и проведения мероприятия. Это позволяет достичь максимального эффекта при подготовке всех частей мероприятия, добиться координации в сроках исполнения услуг и единого понимания необходимости, уместности, логики и баланса всех действий, элементов, частей корпоративного мероприятия. Цели корпоративного мероприятия могут быть рациональным и иррациональными. Рассмотрим каждую из них.

Рациональные цели на корпоративном мероприятии:

1. знакомство, введение новых должностей, видом деятельности, линейки продуктов, корпоративных ценностей и символики, представление новых сотрудников, достижений, перспектив, планов развития;

2. формирование желаемого будущего; инициирование или запуск процесса обучения, развития, структурирования; отстранение от прошлого, внедрение инновационных идей, продуктов, ус- 
луг;

3. ребрендинг (смена названия, логотипа, корпоративной символики); следование традициям с восстановлением утраченных смыслов: наставничество, корпоративные ритуалы, система обучения, развития и мотивации сотрудников;

4. организация досуга: управление временем, вниманием, поведением сотрудников, их активное вовлечение в ход корпоративного мероприятия.

К иррациональным целям корпоративного мероприятия можно отнести:

1. адаптация: возможность привыкнуть к чему-либо; войти в обстоятельства времени и места, принять, понять, осознать, запомнить;

2. интеграция: направление на соединение с внешней средой или на внутренние коммуникации, объединение сотрудников, командообразование;

3. целедостижение: опыт совместного достижения сотрудниками бизнес-организации поставленных целей, акцент на том, что деятельность каждого влияет на продвижение общей цели;

4. поддержание ценностных стандартов бизнес-организации: однозначное понимание сотрудниками основных ценностей компании, ее миссии, целей, планов, уникальности и уровня деятельности.

Рациональные и/или иррациональные цели корпоративного мероприятия - адаптация, интеграция, объединение, целедостижение, поддержание ценностных стандартов являются основой содержания корпоративного мероприятия и работают на главную, масштабную, глобальную цель бизнес-организации - формирование и поддержание корпоративной культуры и гармонизация организационной структуры для эффективной и результативной деятельности бизнес-организации.

Установка на достижение поставленных целей предполагает постановку и выполнение определенных и конкретных задач в процессе подготовки и проведения корпоративного мероприятия.

1. Определение организатора корпоративного мероприятия. Выбор основного подрядчика, ивентагентства, берущего на себя основную организационную и творческую нагрузку.

2. Определение круга участников мероприятия, их роли, план действий и уровень участия.

3. Выбор места проведения праздника с учетом всех организационных, технических и творческих задач корпоративного мероприятия.

4. Разработка тайминга, плана, подробной программы и сценария корпоративного праздника.

5. Координация всех частей, элементов корпоративного мероприятия до, вовремя и после его проведения, управление всеми участниками ме- роприятия: подрядчики, артисты, гости, зрители, представители СМИ.

6. Подведение итогов, анализ результатов проведенного корпоративного мероприятия: достижение цели и выполнение задач, анализ ошибок и форс-мажоров, получение обратной связи от всех участников его проведения и сотрудников бизнес-организации, отслеживание изменений в межличностной внутренней коммуникации, изменение психологического микроклимата в коллективе сотрудников, реакция и отзывы в средствах массовой информации.

7. Корректировка системы подготовки и проведения следующих корпоративных мероприятий.

Четкое выполнение вышеизложенного плана подготовки и проведения корпоративного мероприятия гарантирует выполнение заложенных в него целей и задач, успех у сотрудников бизнес-организации, универсальность применения как в формате «офлайн», так и в формате «онлайн».

До конца 2020 года большинство корпоративных мероприятий проводилось в формате «офлайн», с введением ограничений на проведение массовых мероприятий с марта 2020 года актуальным и востребованным стало проведение корпоративных мероприятий в формате «онлайн». Уточним что означают данные форматы и в чем их различие.

Офлайн - (англ. offline, «отключённый от сети) - термин, применяющийся к чему-либо не связанному с Интернетом, противоположно термину «онлайн». Изначально - «онлайн» и «офлайн» («на линии» и «вне линии») - англоязычные технические термины, обозначающие состояние специального электронного оборудования, но к настоящему времени они вошли во многие языки мира как общеупотребительные слова. Применительно к организации и проведению мероприятий: мероприятия «офлайн» - это мероприятия, проходящие в традиционном формате, с активным вовлечением в непосредственное живое общение максимального количество его участников и без применения сети Интернет.

«Онлайн» корпоративные мероприятия проводились и до 2020 года как деловые события: конференции, вебинары, семинары, прямые включения гостей с докладом, приветствием или поздравлением для всех участников корпоративного мероприятия.

Перевод большинства бизнес-организаций на удаленный формат деятельности, отсутствие возможности проведения мероприятий в привычном формате и потребность сохранить традиции проведения корпоратив- 
ных мероприятий развернуло вектор поиска решения этой ситуации в онлайн форматы. Появились онлайнстудии и контент-студии, оборудованные видео-, аудиоаппаратурой, световыми приборами, видео-экранами и предлагающие свои ресурсы для создания видео-контента, в том числе для записи или съемки в прямом эфире корпоративных мероприятий различных видов и жанров. Более конкретно о процессе и проблемах организации и подготовки корпоративных мероприятий мы поговорим во второй и третьей главах нашего исследования

В настоящий момент мы наблюдаем появление но- вых возможностей для организации корпоративных мероприятий, как важной части корпоративной культуры, через активное привлечение информационных технологий в формате онлайн.

Продуманная система организации и проведения корпоративных мероприятий играет важную роль в процессе культивирования корпоративных ценностей, в формировании лояльности и доверия сотрудников руководству бизнес-организации, повышении мотивации и уровня удовлетворения от работы в бизнес-организации, объединения сотрудников для эффективной и результативной деятельности бизнес-организации.

\section{ЛИТЕРАТУРА}

1. Жемчугов А.М. Организационная культура / А.М. Жемчугов, М.К. Жемчугов // Проблемы экономики и менеджмента. - 2012. - № 10. - С. 4-26.

2. Колос А.Л. Место и роль организационной культуры в антикризисном управлении предприятием / А.Л. Колос, Д.А. Репка // Приборостроение 99: материалы междунар. науч.-техн. конф., Калуга, 1999. - (спец. вып.). - С. 8-11.

3. Корпоративная культура: учеб. пособие / под ред. А.Г. Поршнева, Б.3. Мильнера. - Москва: Изд-во Гос. ун-та управления, 2003. - 278 с.

4. Могутнова Н.Н. Корпоративная культура: понятие, подходы / Н.Н. Могутнова // Социологические исследования. - 2015. - № 4. - С. $132-139$.

5. Погребняк В.А. Культура организации как объект регулярного управления / В.А. Погребняк // Вопросы управления предприятием. - 2005. - № 1 (13). C. 59-64.

6. Смирнова И.А. Корпоративная культура организации: психолого-акмеологические основы формирования и развития корпоративной культуры организации / И.А. Смирнова. - Москва : КДУ, 2009. - 194 с.

7. Спивак В.А. Корпоративная культура: теория и практика / В.А. Спивак. - Санкт-Петербург: Питер, 2001. - 345 с

8. Шейн Э. Организационная культура и лидерство / Э. Шайн. - Санкт-Петербург: Питер, 2002. - 336 с.

9. Шекшня С.В. Управление персоналом современной организации / С.В. Шекшня. - Москва: Интел-синтез, 1996. - 297 с.

10. Шинкаренко 0.Н. Корпоративная культура: мифы и реальность / О.Н. Шинкаренко // Кадры предприятия. - 2011. - №9. - С. 34-35.

(с) Кирьянова Ольга Александровна (s-slon@bk.ru). 